DOI: $10.22616 /$ REEP.2020.018

\title{
The Relationship between Implicit and Explicit Attitudes towards Criminal Violence and Attachment Styles
}

\author{
Laura Simane-Vigante ${ }^{1}$ Mg.psych.; Irina Plotka ${ }^{2}$ Dr.psych.; Nina Blumenau ${ }^{3}$ Dr.sc.ing. \\ Baltic International Academy, Latvia \\ 1.simane@inbox.lv¹; irinaplotka@inbox.lv²; nina.blum@gmail.com ${ }^{3}$
}

\begin{abstract}
Attachment system is an emotion regulation device that helps to regulate the emotions and the expression of it. In forensic psychology attachment security/insecurity is studied, because it tends to be a predictive moderator of violent offenses. Attitudes towards violence are important predictors of violent behaviour. The aim of the study is to research the relationship between the results of implicit and explicit measurements of attitudes towards criminal violence and attachment styles of violent sentenced male offenders and non-offenders. Five research questions have been set. 88 males took part in the research. The whole sample consisted of two groups: "Sentenced" $(\mathrm{N}=49)$ and "Not Sentenced" $(\mathrm{N}=39)$. A specially designed Violence Self-concept IAT was used as well as self-report measures (Criminal Attitudes towards Violence Scale and Vulnerable Attachment Style Questionnaire). The results showed a partial correspondence between the results of implicit and explicit measurements of attitudes towards violence. The difference of the strength of explicit criminal attitude towards violence between the groups "Not Sentenced" and "Sentenced" was not revealed, but implicit associations of oneself with non-violence are more pronounced in the "Not Sentenced" group. In the "Not Sentenced" group, the part of participants with the secure attachment style is greater than in the "Sentenced" group. The relationships between measurements of attachment styles (secure, insecure avoidant and insecure anxious) and attitudes towards criminal violence only with explicit attitudes were revealed. Non offenders with secure attachment style have the least pronounced explicit attitudes towards criminal violence, compared with the males with insecure attachment styles. The results can be used for forensic practitioners in order to improve the process of re-socialization.
\end{abstract}

Keywords: attitude towards violence, attachment style, self-concept implicit test, criminal violence, forensic psychology.

\section{Introduction}

The attachment theory is taught in almost every discipline of psychology. It explains psychological and neuropsychological processes starting in childhood and continuing throughout the lifespan. Attachment theory was firstly developed by J. Bowlby $(1984,1988)$, further expanded by M. Ainsworth (Ainsworth et al., 1978), who, with the help of the experiment "Strange situation" firstly talked about children attachment styles. C. Hazan and P.R. Shaver (1994) explained adult attachment in regard to romantic relationships, identifying three attachment styles (Secure, Insecure Avoidant and Insecure Anxious-ambivalent) and K. Bartholomew and L.M. Horowitz (1991) adapted the original three attachment styles in to four attachment styles (Secure, Preoccupied, Dismissing and Fearful). Attachment is formed in childhood on the basis of an affectionate bond with a caregiver (the "safe base"). Separation anxiety takes place if the caregiver is absent and if he or she is not responsive to the needs of the child insecure attachment is formed. It is analysed that not the quantity, rather the quality of interaction with the caregiver is the most important. If the emotional needs of the child are met, secure attachment style is formed and vice versa, see detailed analysis of the attachment theory in L. Simane-Vigante, I. Plotka, N. Blumenau (2018).

Why is it necessary to study attachment in regard to attitudes towards violence in the sample of violent male offenders? Attitudes towards violence are important, because they may help explain violent actions and invest in predicting violent behaviour (Bowes, McMurran, 2013). M. Ansbro (2008) has stated that attachment theory provides an insight in the regulation of psychological processes of the offenders (for example, mood and empathy), which is beneficial for forensic practitioners. T. Ross and F. Pfäfflin have come to a conclusion that attachment theory "provides the framework for a developmental perspective on violent behaviour” (Ross, Pfäfflin, 2007, 90). 
M. Mikulincer and P.R. Shaver state that "(..) attachment system is, in itself, an emotion regulation device" (Mikulincer, Shaver, 2007, 190). Dangerous situations or possible threats activate the system automatically and makes the individual to seek proximity in order to deal with the threatening situation and regain emotional balance. Attachment security provides the ability to develop flexible regulatory processes that help to experience and express emotions in a healthy manner. In contrast, attachment insecurity contributes to misrepresentation of healthy emotional experience, unconscious suppression of emotions and poor coping skills. The results of the research in the field of Neuropsychology show that the release of cortisol (stress hormone) has a relationship with the security of the attachment, thus insecurely attached individuals have chronically high levels of cortisol, but for securely attached individual's cortisol is released and fades off quickly, indicating the ability to deal with anxiety (Spangler, Schieche, 1998).

An important topic in adult attachment research is anger experience and management. J. Bowlby (1973) stated that anger is a normal response of a child to separation from the caregiver. Anger is expressed mostly to gain the attention of the attachment figure and regain the necessary proximity. Analysis showed that for adults, on the basis of attachment security, anger can be constructive or destructive and expressed in functional or dysfunctional ways. Functional forms of anger (expressed mainly by securely attached individuals) are mostly motivated by maintaining relationships and indicating the necessity of change in partner's behaviour. It is expressed mainly as a problem-solving discussion without any hatred or the use of violence. Dysfunctional forms of anger (experienced manly by insecurely attached individuals) include resentment, revenge, hatred and deliberate physical or emotional aggression (Johnson, Makinen, Millikin, 2001). Research show that there is association between attachment security and more constructive and less-aggressive responses to provocations and self-reported aggression (Barrett, Holmes, 2001; Meesters, Muris, 2002). In other words, individuals with insecure attachment style more often use violence as a physical replacement for absent psychological mechanisms designed to moderate expressions of anger and other negative feelings (Parsons, 2009).

Regarding to the sample of offenders, attachment alone does not predict violent attitudes that lead to violent, criminal behaviour, there are many other factors, both situational and personal that could trigger the behaviour. Although, many studies have proven that attachment acts a potential moderator of violent attitudes and violent behaviour starting with J. Bowlby's early work (1944) dedicated to early attachment and later delinquency. He was researching young offenders and concluded that an absence of a secure attachment figure was connected to lack of empathy and inability to form close relationships. The lack of quality of parental care (the child experiencing neglect, abu se or loss) was also found as an important factor for violent behaviour in more recent research (Farrington, 2007; Boswell, 1998). A meta-analysis of studies was concluded aimed at proving the existence of the relationship of criminal behaviour and attachment styles. As a result of the analysis, they found that insecure styles of attachment are largely associated with delinquency in boys and girls (Hoeve et al., 2012).

Many current studies have found that in the sample of offenders the percentage of insecure attachment stiles is significantly higher than the secure attachment stile, when comparing samples of offenders and non-offenders, non-offenders are more securely attached than the offenders (Ross, Pfäfflin, 2007). Researchers debate on the type of offence committed. Some argue that sex offenders mostly are insecurely attached (Simons, Wurtele, Durham, 2008), others state that all types of offenders are likely insecurely attached (Baker, Beech, 2004; Miller, Klockner, 2019). The result in the sample of violent offenders has also been confirmed in our previous research (Simane-Vigante, Plotka, Blumenau, 2018).

The reason, why offenders are usually less securely attached also could be that secure attachment provides an important element for emotional and cognitive development. Children are not born with the ability to manage emotions and, therefore, they need the care of the attachment figure to develop the ability to adequately regulate, control and respond to stressful situations. When these skills do not develop properly in childhood, this leads to difficulties in self-regulation and a tendency to look for inadequate ways to control and overcome negative feelings leading to aggression or self-harming behavior in adulthood (Briere, 1992). The emotional reaction of a caregiver to baby's actions (falling over, smiling, waving) triggers a mechanism, when a baby starts to form the ability to access one's own emotions, thoughts and feelings, thus goes on to enhance a meta-cognitive ability. Insecurely attached individuals find it challenging to reflect (to "think about thinking") and the emotional vocabulary is limited, which is also evident when working with offenders (Fonagy, 2004). If an individual has an 
attachment object, who is able and willing to understand one's emotional state, the individual can become an adult, who can do the same for others (understand one's own emotions and the emotions of others and feel empathy). If this is not the case, a different strategies of problem solutions are adopted that do not include the access of one's own or others state of mind. It is evident that offenders lack the empathy for their victims and are not able to reflect on their problems, deal with stress or apply any other method in reducing anxiety or stress apart from violence or substance abuse (Ansbro, 2008).

It is possible to conclude that insecurely attached individuals lack empathy, the ability to regulate and reflect their own emotions and actions, the application for positive coping-mechanisms that does not include violence, and suffer more from anxiety, stress and anger. All these factors can benefit for violent criminal behaviour. That is why it is necessary to study attachment of violent offenders.

The theoretical analysis has shown that in order to study the relationship of attachment styles and attitudes towards violence mostly self-assessment procedures have been used. In order to increase the validity of the psychological construct as attitude towards violence, it is necessary to use behavioural measures as implicit measures combined with self-assessment procedures. In our previous research (Plotka, SimaneVigante, Blumenau, 2018) the relationship between attitudes (explicit and implicit) towards criminal violence and attachment styles of convicted violent males was investigated. In the current study the self-concept implicit association test has been improved. We implement the model of three attachment styles - Secure, Insecure Avoidant and Insecure Anxious (Hazan, Shaver, 1994). The aim of this study is to research violent attitudes and attachment styles of violent sentenced male offenders and non-offenders.

\section{Methodology}

The research questions: (1) Is there correspondence between the results of measuring implicit associations related to criminal violence using Self-Concept IAT and self-assessment criminal attitudes towards violence among sentenced and not sentenced males? (2) Are there differences in implicit and explicit measurements of criminal attitudes between groups of sentenced and not sentenced males? (3) Are there differences in secure, insecure avoidant and insecure anxious attachment styles between groups of sentenced and not sentenced males? (4) Is there a relationship between implicit associations of self with criminal violence measured by Self-Concept IAT and attachment styles? (5) Is there a relationship between self-reported attitudes towards criminal violence and attachment styles?

Participants. 88 males. Group "Sentenced" - 49 sentenced males, $18-57$ years $(M d n=30)$, who were all sentenced for violent crimes (murder, assault, robbery) at least once. Group "Not Sentenced" -39 previously not sentenced males, 16-60 years $(M d n=34)$, who have never been sentenced for any criminal offenses and their daily job did not involve violence.

Explicit methods. linguistically adapted in Latvian and Russian:

- Criminal Attitudes towards Violence Scale (CAVS) (Polaschek, Collie, Walkey, 2004). Cronbach`s alpha $=0.89$.

- Vulnerable Attachment Style Questionnaire (VASQ) (Bifulco et al., 2003). Cronbach`s alpha $=0.80$.

Implicit method. The Violence Self-concept IAT was designed with the aim of measuring associations of self-violent/ peaceful and others-violent/peaceful. The procedure was created in Latvian and Russian languages and it combined verbal target categories (self-others) and pictorial attributes (violence-peace). Cronbach`s alpha $=0.97$.

The attributes (Violent-peaceful) was represented by 12 pictures purchased from "Shutter stock" and "Stock Illustrations". The images were 10x15 cm and were black and white silhouettes of either an action involving physical non-sexual violence (strangle, stab, fight, hit, shoot, cut) or an action involving peaceful activity (fishing, holding a sleeping baby (calming), sleeping, playing with children, sailing and swimming). The images of non-sexual physical violence were based on the items of Criminal Attitudes towards Violence scale (CAVS) (Polaschek, Collie, Walkey, 2004) that measures the same variable. Black and white pictures were used, because after viewing countless detailed, graphic, colourful pictures of violent acts, researchers decided that pictures like that are too disturbing for the participants and it would be unethical to expose them. 
Peaceful pictures were picked according to actions that are peaceful and do not involve high adrenalin activities (as skiing, parachute jumping), competitive activities (e.g., team sports, racing or boxing) and women (couple activities). All of the pictorial stimuli were specially selected for a male audience.

Apparatus. The Self-concept IAT was designed in Baltic International Academy in the Laboratory of Implicit Measurements on the apparatus: Certified licensed software E-Prime 2®. The categories and attributes were presented on a notebook HP 15-AY002NY with WLED backlight type screen, the size of which is 15.6 inches with 1366 x 768-pixel resolution.

Research design. The Self-Concept IAT was designed using seven trial blocks (Table 1). Performance of the implicit method took on average from 10 to 20 minutes. Participant's reaction time (RT) was registered. Each stage was preceded by a set of instructions concerning the dimensions of the categorization task and the appropriate key responses. Before the start of the research, a participant was given on a computer monitor the general instructions and specific instructions before each of the tasks.

The IAT procedure was shortened as much as possible in order to take in to account the features of the sample of low-educated individuals with limited attention span.

Table 1

The procedure of Violence Self-concept IAT

\begin{tabular}{|c|c|c|c|c|}
\hline Block & Trials & Function & Left-key response " $Q$ " & Right- key response "P" \\
\hline 1 & 10 & Practice & $\mathrm{Me}(\mathrm{v})$ & Others (v) \\
\hline 2 & 15 & Practice & Peace $(w)$ & Violence(w) \\
\hline 3 & 40 & Test & $\operatorname{Me}(v)+\operatorname{Peace}(w)$ & Others $(v)+$ Violence $(w)$ \\
\hline 4 & 45 & Test & $\operatorname{Me}(v)+\operatorname{Peace}(w)$ & Others $(v)+$ Violence $(w)$ \\
\hline 5 & 20 & Practice & Others $(\mathrm{v})$ & $\operatorname{Me}(\mathrm{v})$ \\
\hline 6 & 40 & Test & Others(v)+ Peace(w) & $\operatorname{Me}(v)+$ Violence $(w)$ \\
\hline 7 & 45 & Test & Others(v)+ Peace(w) & Me(v)+ Violence(w) \\
\hline
\end{tabular}

Note. $\mathrm{w}$ - visual category, $\mathrm{v}$ - verbal category.

To assure internal validity of the IATs described, all main parameters e.g., intervals between stimulus, stimulus display time, stimulus word count, shrift, chromatic background characteristics remained constant, while changes in independent conditions occurred (during the changes in experimental conditions).

\section{Results and Discussion}

\section{Variables}

\section{Group: Not Sentenced, Sentenced.}

$D$ : the measure of implicit associations of self with criminal violence (Rudman, 2011). $D \geq 0.15$ implicit associations with non-violence, $D \leq-0.15$ - implicit associations with violence, $-0.15<D<0.15-$ no effect (that means that implicit associations are either weak or conflicted) (Figure 2).

CAVS: the strength of the self-reported criminal attitude towards violence. Quartiles are $Q_{1}=42, Q_{3}=62.75$. If $C A V S \leq 42$ the level of explicit attitude towards violence is low, if $C A V S \geq 62.75$ - high (Figure 3).

Vulnerability: (Vulnerability $>57$ high, Vulnerability $\leq 57$ low). Two scales: Insecurity (Insecurity $>30$ high, Insecurity $\leq 30$ low) and Proximity Seeking - (Proximity Seeking $>27$ high, Proximity Seeking $\leq 27$ low).

Attachment Styles: Secure Style (Insecurity $\leq 30$ ), Insecure Anxious Style (Insecurity > 30 and Proximity Seeking > 27), Insecure Avoidant Style (Insecurity > 30 and Proximity Seeking $\leq 27$ ) (Figures 4-5).

\section{Data Analysis}

To select the statistical research methods, the indicators of descriptive statistics, outliers and extremes were analysed, and the normality of the data distribution was checked. It was found that parametric statistics methods can be used for subsets, where the following participant is not present: code $\mathrm{n} 3$ (age 37 years old, $D=-0.74$ - high pro-violence, group "Not sentenced", CAVS - medium, secure attachment style). It is also possible to use ANOVA to study the relationship between nominal and ordinal variables. The using of Chi-square test turned out to be impossible, since $67 \%$ cells have expected count less than 5 . 
To answer the first research' question the correlation coefficients Pearson $(r)$ and Spearman $\left(r_{\mathrm{S}}\right)$ were calculated (see Table 2). A negative correlation coefficient corresponds to the consistency of measurements results using the self-concept IAT and CAVS.

Table 2

The correspondence of the measurements' results using Self-concept IAT and CAVS: Spearman $r_{\mathrm{S}}$ and Pearson $r$ correlation coefficients for the entire sample and its parts: the groups "Not sentenced", "Sentenced"

\begin{tabular}{|l|c|c|}
\hline \multicolumn{1}{|c|}{ Group } & Correlation Coefficient & Effect size \\
\hline Total & $\mathrm{r}_{\mathrm{S}}(88)=-0.19, p=0.084$ & small \\
\hline Not Sentenced & $\mathrm{r}_{\mathrm{S}}(39)=-0.13, p=0.42, \mathrm{~ns}$ & small \\
\hline Sentenced & $\mathrm{r}_{\mathrm{S}}(49)=-0.26, p=0.075$ & almost medium \\
\hline
\end{tabular}

To answer the second and third research questions, the Mann-Whitney U-test and $\varphi^{*}$ - Fisher's angular transformation test were used (effect size Cohen's $h$ interpretation: 0.2-small; 0.5- medium; 0.8-large).

Implicit associations of self, related to criminal violence

To study the differences of the participant's distributions of the implicit associations categories: (with "non-violence", with "pro-violence" and with either weak or conflict implicit association - "no effect"), (Figure 1) in the groups "Not Sentenced" and "Sentenced", the Fisher's angular transformation test was used (Tables 3, 4).

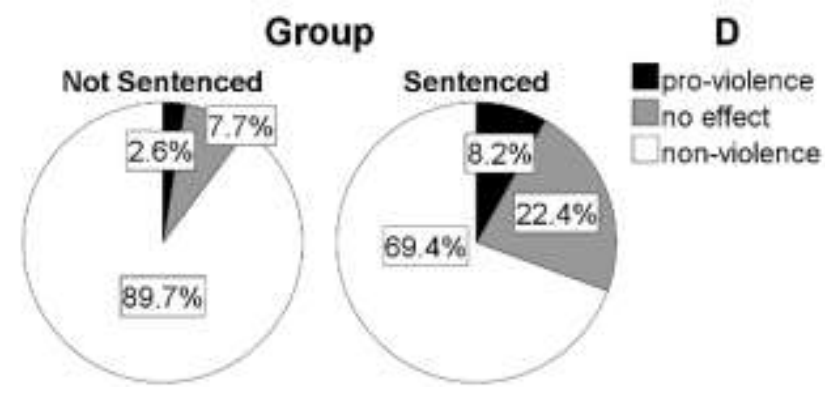

Figure 1. Distributions of participants with different implicit associations towards violence (non-violence, no effect, pro-violence) in two groups: "Not Sentenced" and "Sentenced".

Table 3

Implicit associations self with criminal violence. Comparison of participants' percent between two groups with Fisher's angular transformation test

\begin{tabular}{|l|c|c|l|c|}
\hline $\begin{array}{c}\text { Implicit } \\
\text { associations } \\
\text { with self }\end{array}$ & $\begin{array}{c}\text { Not } \\
\text { Sentenced }\end{array}$ & Sentenced & $\varphi^{*}$-statistic, $\boldsymbol{p}$-value, Cohen's $\boldsymbol{h}$ & Effect size \\
\hline pro-violence & $2.6 \%$ & $8.2 \%$ & $\begin{array}{c}\varphi^{*}=1.20, p=0.23, \mathrm{~ns}, h= \\
0.26\end{array}$ & small \\
\hline no effect & $7.7 \%$ & $22.4 \%$ & $\varphi^{*}=1.98, p=0.048, h=0.43$ & small, near to medium \\
\hline non-violence & $89.7 \%$ & $69.4 \%$ & $\varphi^{*}=2.43, p=0.015, h=0.52$ & medium \\
\hline
\end{tabular}

Table 4

Implicit associations self with criminal violence. Comparison of participants' percent within groups with Fisher's angular transformation test

\begin{tabular}{|c|c|c|c|c|}
\hline Group & \multicolumn{2}{|c|}{ Implicit associations with self, \% } & $\varphi^{*}$-statistic, $\boldsymbol{p}$-value, Cohen's $\boldsymbol{h}$ & Effect size \\
\hline \multirow{3}{*}{ 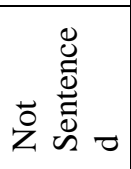 } & pro-violence 2.6 & no effect 7.7 & $\varphi^{*}=1.06, p=0.29, \mathrm{~ns}, h=0.24$ & small \\
\hline & pro-violence 2.6 & non-violence 89.7 & $\varphi^{*}=9.57, p<0.001, h=2.17$ & large \\
\hline & no effect 7.7 & non-violence 89.7 & $\varphi^{*}=8.51, p<0.001, h=1.93$ & large \\
\hline \multirow{2}{*}{$\begin{array}{l}\ddot{\bar{\nu}} \\
\tilde{\Xi}\end{array}$} & pro-violence 8.2 & no effect 22.4 & $\varphi^{*}=2.02, p=0.044, h=0.41$ & small \\
\hline & pro-violence 8.2 & non-violence 69.4 & $\varphi^{*}=6.88, p<0.001, h=1.39$ & large \\
\hline
\end{tabular}




\begin{tabular}{|l|c|c|c|c|}
\hline & no effect 22.4 & non-violence 69.4 & $\varphi^{*}=4.86, p<0.001, h=0.98$ & large \\
\hline
\end{tabular}

Implicit associations of oneself with non-violence are more pronounced in the "Not Sentenced" group $(M d n=0.46)$ than in the "Sentenced" group $(M d n=0.30): U=738.0, p=0.068$, the effect size $r=0.19$ is small.

\section{Explicit attitudes towards criminal violence}

To study the differences in the distributions of participants by CAVS categories: low, high, medium in the groups "Not Sentenced" and "Sentenced" (Figure 2) the Fisher's angular transformation test was used (Table 5).

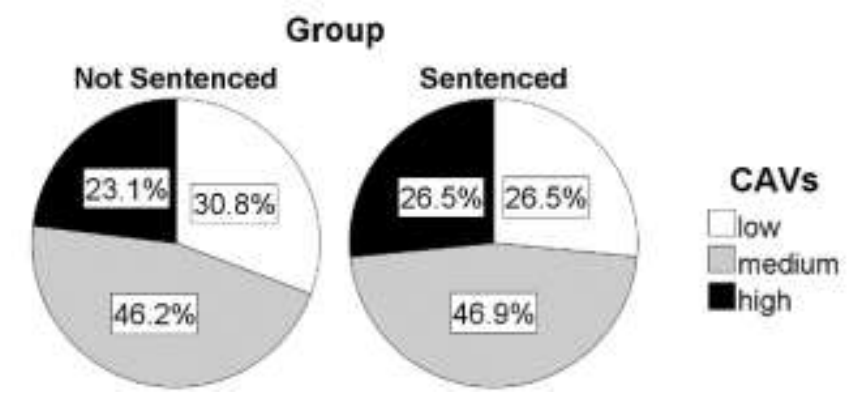

Figure 2. Distributions of participants with different levels of the strength of explicit criminal attitude towards violence (low, medium, high) in two groups: "Not Sentenced" and "Sentenced".

At the corresponding levels of the strength of explicit criminal attitude towards violence (low, medium, high), the percentages of participants in the Sentenced group $(23.1 \%, 46.2 \%, 30.8 \%)$ and the Not Sentenced group $(26.5 \%, 46.9 \%, 26.5 \%)$ have random differences with the size of the Cohen's $h$ effect $(0.09,0.02,0.14)$ - there is no effect.

Table 5

\section{Explicit attitudes towards criminal violence. Comparison of participants' percent within groups} with Fisher's angular transformation test.

\begin{tabular}{|l|c|c|c|c|}
\hline \multirow{2}{*}{ Group } & \multicolumn{2}{|c|}{$\begin{array}{c}\text { Explicit attitudes towards } \\
\text { criminal violence, \% }\end{array}$} & $\varphi^{*}$-statistic, $\boldsymbol{p}$-value, Cohen's $\boldsymbol{h}$ & Effect size \\
\hline \multirow{3}{*}{$\begin{array}{l}\text { Not } \\
\text { Sentenced }\end{array}$} & low 30.8 & medium 46.2 & $\varphi^{*}=1.40, p=0.32, \mathrm{~ns}, h=0.16$ & small \\
\cline { 2 - 5 } & low 30.8 & high 23.1 & $\varphi^{*}=1.40, p=0.16, \mathrm{~ns}, h=0.32$ & small, near to medium \\
\cline { 2 - 5 } & medium 46.2 & high 23.1 & $\varphi^{*}=2.17, p=0.030, h=0.49$ & medium \\
\hline \multirow{3}{*}{ Sentenced } & low 26.5 & medium 46.9 & $\varphi^{*}=2.12, p=0.034, \mathrm{~ns}, h=0.43$ & small, near to medium \\
\cline { 2 - 6 } & low 26.5 & high 26.5 & $\varphi^{*}=0.00, p=1.00, h=0.00$ & no effect \\
\cline { 2 - 5 } & medium 46.9 & high 26.5 & $\varphi^{*}=2.12, p=0.034, \mathrm{~ns}, h=0.43$ & small, near to medium \\
\hline
\end{tabular}

Vulnerable, insecure, proximity seeking

The results of differences investigation using the Mann-Whitney $U$-test are shown in the Table 6 Effect size's $r$ interpretation is: 0.10 - small, 0.30 - medium, 0.50 - large.

Table 6

The results of differences investigation using the Mann-Whitney U-test

\begin{tabular}{|l|c|c|c|}
\hline & "Not Sentenced" & "Sentenced" & $\boldsymbol{U}$-statistic, $\boldsymbol{p}$-value, effect size $\boldsymbol{r}$ \\
\hline Vulnerability & $M d n=60.0$ & $M d n=64.0$ & $U=758.0, p=0.097, r=0.18$ \\
\hline Insecurity & $M d n=32.0$ & $M d n=35.0$ & $U=808.5, p=0.22, \mathrm{~ns}, r=0.13$ \\
\hline Proximity Seeking & $M d n=29.0$ & $M d n=31.0$ & $U=768.0, p=0.11, \mathrm{~ns}, r=0.17$ \\
\hline
\end{tabular}

\section{Secure, Insecure Avoidant and Insecure Anxious attachment styles}

To study the differences in the distributions of participants by attachment styles: Secure, Insecure Avoidant and Insecure Anxious (Figures 3,4) in the groups "Not Sentenced" and "Sentenced" the Fisher's angular transformation test was used (Table 7). 


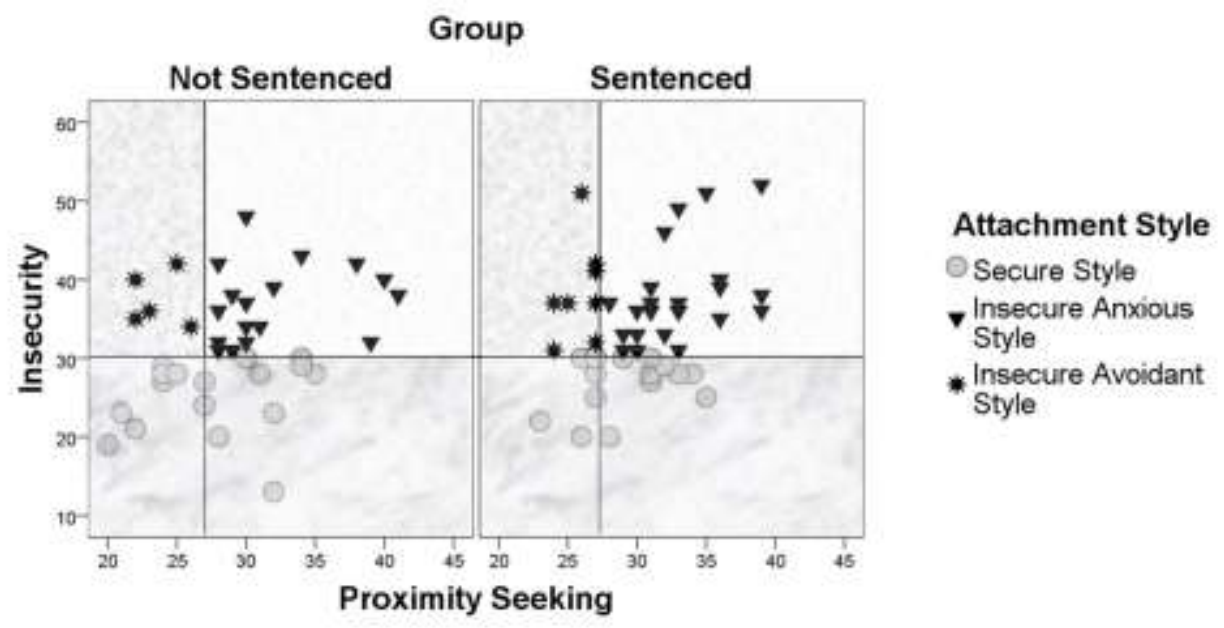

Figure 3. Attachment styles: scatter. Groups: "Not Sentenced" and "Sentenced".

Group
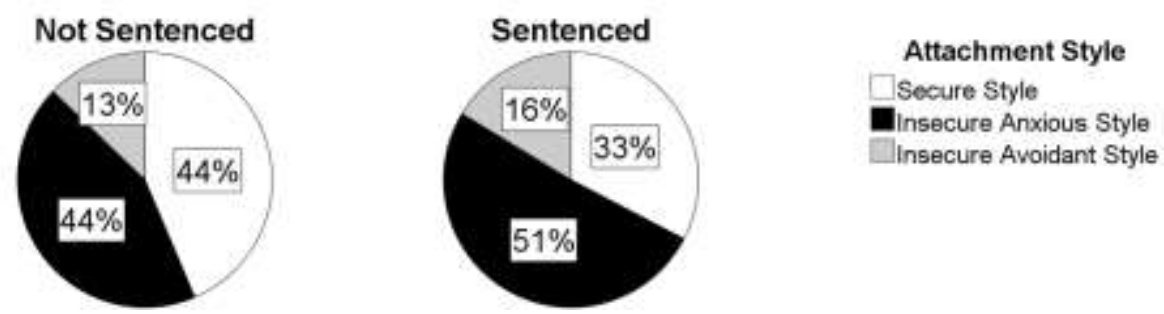

Figure 4. Distribution of participants by Attachment Styles (Secure, Insecure Anxious, Insecure Avoidant) in two groups: "Not Sentenced" and "Sentenced".

The small effect (statistically insignificant) of the fact that in the group "Not Sentenced", the percentage of participants with secure attachment style (44\%) is bigger than in the group "Sentenced" (33\%) was found: $p=0.29, \mathrm{~ns}, h=0.23$.

Table 7

Attachment Styles. Comparison of participants' percent within groups with Fisher's angular transformation test. Effect size Cohen's $h(0.20$ - small, 0.50 - medium, 0.80 -large $)$

\begin{tabular}{lccc}
\hline \multicolumn{1}{c}{ Group } & \multicolumn{2}{c}{ Attachment Styles, \% } & $\varphi^{*}$-statistic, $\boldsymbol{p}$-value, Cohen's $\boldsymbol{h}$ \\
\hline \multirow{2}{*}{$\begin{array}{l}\text { Not } \\
\text { Sentenced }\end{array}$} & Secure 43.6 & Insecure Anxious 43.6 & $\varphi^{*}=0.00, p=1.00, \mathrm{~ns}, h=0.00$ \\
& Secure 43.6 & Insecure Avoidant 12.8 & $\varphi^{*}=3.13, p=0.002, h=0.71$ \\
& Insecure Anxious 43.6 & Insecure Avoidant 12.8 & $\varphi^{*}=3.13, p=0.002, h=0.71$ \\
\hline \multirow{2}{*}{ Sentenced } & Secure 32.7 & Insecure Anxious 51.0 & $\varphi^{*}=1.85, p=0.064, \mathrm{~ns}, h=0.37$ \\
& Secure 32.7 & Insecure Avoidant 16.3 & $\varphi^{*}=1.90, p=0.057, h=0.38$ \\
& Insecure Anxious 51.0 & Insecure Avoidant 16.3 & $\varphi^{*}=3.76, p<0.001, h=0.76$ \\
\hline
\end{tabular}

To answer the fourth and fifth research questions the correlation coefficients Pearson $(r)$ and Spearman $\left(r_{\mathrm{s}}\right)$ were calculated (see Table 8 ) and one-way ANOVA was used.

The tendency to relationship between the implicit associations of self with criminal violence with proximity seeking for sentenced males was found: $r(49)=0.24, p=0.10$. Effect size is small, near to medium.

The relationships between self-reported attitudes towards criminal violence (CAVS) with attachment styles only in the group "Not Sentenced" were found: CAVS - Vulnerability: $\mathrm{r}_{\mathrm{s}}(39)=0.39, p=0.014$, effect size is between medium and large; CAVS - Insecurity: $\mathrm{r}_{\mathrm{s}}(39)=0.48, p=0.002$, effect size is large. The relationships between $C A V S$ and the variable Attachment styles (Secure, Insecure Anxious, Insecure Avoidant): $F(2,36)=8.64, p=0.001, \eta^{2}=0.32$. Effect size is large. Using the Post Hoc Scheffe test it was found, that the not sentenced males with secure style have the smallest CAVS mean value $(\mathrm{M}=40.4, \mathrm{SD}=10.9)$ compared with the CAVS mean of men with an anxious attachment style 
$(M=57.8, S D=15.0, p=0.001)$ and compared with the CAVS mean of men with an avoidant attachment style $(M=55.2, S D=7.12, p=0.082)$, (see Figure 5).

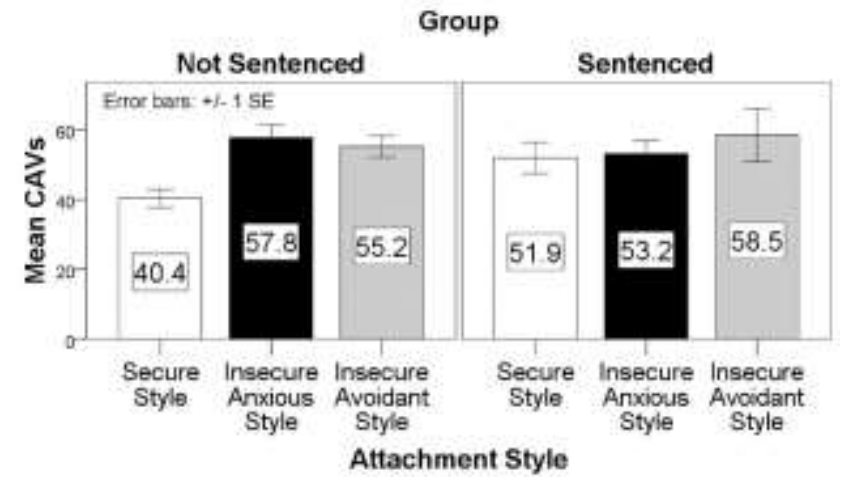

Figure 5. The means of CAVS in dependence on attachment style in two groups: "Not Sentenced" and "Sentenced".

The answer to the first research question. There was a tendency to correspondence between the implicit and explicit measurements of attitudes towards criminal violence revealed for the whole sample as well as the group offenders and non offenders (the effect sizes are small). The results showed compliance with the implicit and explicit measurement of constructs studied, evaluated with the correlation coefficients, the values of which fall within the permissible range of 0.12 to 0.72 (Rudman, 2011). Due to a small enough sample size in this research, the focus was more on the value of correlation coefficients, rather than of their statistical significance. The results are confirmed by laboratory research as well that have shown that there are only weak or medium (but generally positive) correlation between the IAT and explicit measurements of the same construct (Bosson, Swann, Pennebaker, 2000; Greenwald, McGhee, Schwartz, 1998; Karpinski, Hilton, 2001; Ottaway, Hayden, Oakes, 2001).

In previous researches when IAT was used in order to measure violent attitudes of offenders no consistency between the explicit and implicit measurement results were found. In the study of S. Blumenthal and colleagues, there was no correlation between the results of IATs and explicit measures of violence. The researchers hypothised that the lack of correlation could be because of psychometric properties of IATs or poor explicit measurements of violence, although the reliability and consistency of the instruments turned out to be satisfying. The researchers also noted that violence in itself is a very hard topic to measure and participants, even in a prison setting, want to provide more socially desirable results and appear less violent, when completing the self-report procedure (Blumenthal et al., 2019). The main aim of the study of D. Polaschek and colleagues was to compare scores on violence-related IATs with self-report scales. The scores of IAT and self-report scales had no relationship and the authors concluded that in their case explicit and implicit measures of aggressive cognition are not related (Polaschek et al., 2010). In future research it is necessary to take in to account what conditions and variables determine when implicit and explicit attitudes converge (Fazio, Olson, 2003; Rudman, 2011).

The answer to the second research question. For both groups (offenders and non-offenders) implicit non-violence attitudes were mostly revealed, meaning that participants mostly associate themselves with the attribute "peace", rather than "violence". This result is consistent with D. Polaschek and colleagues (Polaschek et al., 2010) findings that the participants (violent male offenders) had preference for the nonviolence category on both IATs that they used. Other studies using Implicit Association tests on a sample of violent criminals also found out that most people have an automatic cognitive association that violence is bad (Gray et al., 2003; Plotka, Simane-Vigante, Blumenau, 2018). This effect was considerably less significant in sample of offenders, who had committed murder and were classified as psychopathic (Snowden et al., 2004). The results of the present study indicate that although the implicit associations were mainly non-violent for both groups, there was a statistically significant difference found between groups, meaning that the percentage of the participants with implicit associations of themselves with nonviolence is higher among the non-convicted males, but for the offenders. Also, a significant difference between pro-violence attitudes and "no effect" was found in the sample of non-offenders. The percentage of participants with implicit associations of themselves with violence (pro-violence attitude) or with weak or conflicting implicit associations of themselves with violence ("no effect") is greater in the group of 
offenders. This is an interesting never-before seen finding, because usually researchers tend to form only a sample of offenders, when using implicit measurement methods measuring violence (Blumenthal et al., 2019, Polaschek et al., 2010). The fact that there is a significant difference of implicit attitudes of violence between the groups, means that it is essential to form a control group in further research.

However, the difference of the strength of explicit criminal attitude towards violence between the groups "Not Sentenced" and "Sentenced" was not revealed. The percentage of participants' distribution by the levels of the strength of explicit criminal attitude within both groups are not much different. In both groups, the percentage of participants with medium strength of explicit criminal attitude towards violence is the largest. In the "Sentenced" group, it is statistically significantly higher than the percentage of participants with high strength of the explicit criminal attitude and the percentage of participants with low strength of the explicit criminal attitude. In the "Not Sentenced" group, it is statistically significantly higher than the percentage of participants with high strength of explicit criminal attitude and statistically slightly higher than the percentage of participants with low strength of explicit criminal attitude.

The answer to the third research question. A small effect was found (although statistically insignificant) that the percentage of participants with the secure attachment style is greater in the "Not-Sentenced" group. These results are similar to the findings of T. Ross and F. Pfäfflin (2007) that non-offenders are more securely attached than the sample of offenders. Also, in the "Not Sentenced" group, the percentages of participants with secure and insecure anxious attachment styles coincide and statistically significantly exceed the percentage of participants with insecure avoidant attachment styles. For the group "Sentenced" insecure Anxious attachment style was the most common, it exceeds the percentage of participants with secure attachment style and the percentage of participants with secure attachment style exceeds the percentage of participants with insecure avoidant attachment style. Similar studies show that violent offenders are insecurely attached (Baker, Beech, 2004; Miller, Klockner, 2019). Anxiously attached individuals have extreme need for love and closeness, fearing that the partner would not support and abandon them in the time of need that is why they experience extreme jealousy at times (Shaver, Balsky, Brennan, 2000). In regard to emotion control, especially to anger control and anxious attachment style, the anger is usually not expressed in a healthy manner and repressed, resulting in to a complex mixture of emotions like resentment, aggression, self-criticism, panic, sorrow and depression. It has been researched that attachment anxiety is linked to relationship violence (Mikulincer, Shaver, 2007).

The tendencies, that vulnerability of attachment and proximity seeking are more pronounced in the "Sentenced" group than in the "Not Sentenced" group, were found. The effect sizes are between small and medium. Also, the small effect size, that insecurity in the group "Sentenced" exceeds the insecurity in the group "Not Sentenced", was revealed.

The answer to the fourth research question. There was no relationship between implicit associations of self with criminal violence measured by Self-Concept IAT and attachment styles found. Only tendency to positive relationship was found between non-violence and proximity seeking in the sample of sentenced males, meaning that offenders that implicitly associate themselves to non-violence, are prone to more active proximity seeking, but the effect size is too small to tell precisely, extra research is needed.

The answer to the fifth research question. The relationships between self-reported attitudes towards criminal violence (CAVS) with attachment styles were found only in the group "Not Sentenced". Not sentenced males with secure attachment have the least pronounced attitudes towards criminal violence, compared with the insecurely attached males, meaning that non-offenders with a secure attachment style report being less violent than males with insecure attachment styles. It has been stated that secure attachment style has many benefits on an interpersonal level (people are trusting, they engage in clear and open communication, they are able and willing to care for others) and on personal level- a secure sense of self (Mikulincer, Shaver, 2007). As discussed in the introduction about attachment as emotional regulation system, attachment security has a relationship to more constructive and less-aggressive responses to provocations and self-reported aggression (Barrett, Holmes, 2001; Meesters, Muris, 2002) and securely attached individuals less often use violence as a physical replacement for absent psychological mechanisms designed to moderate expressions of anger and other negative feelings (Parsons, 2009).

The limitation of the study: in the present research the sample was non-random. 


\section{Conclusions}

The aim of the study was achieved and the answers to the research questions were obtained.

The attachment system is an emotion regulation device. It helps to regulate the emotion and expression of it. Many researchers have focused on the experience and regulation of anger that could lead to violence and criminal offenses. Attachment security/ insecurity is one of predictive moderators of criminal behaviour, as the studies show that criminal offenders are mostly insecurely attached. Insecurely attached individuals lack empathy, emotion regulation, the ability to reflect their own actions and suffer from anxiety and the inability to apply positive coping strategies to stressful situations.

Attitudes towards violence, especially implicit attitudes, predict behaviour. It is important to study them in a forensic setting to provide more information for the forensic practitioners.

In order to increase the validity of the psychological construct as attitude towards violence, it is necessary to use behavioural measures as implicit measures combined with self-assessment procedures. Specially designed Violence Self-concept Implicit Association test (Self-concept IAT) is an important indirect research method that assess the automatic associations of self with violence and non-violence. It is important to use indirect measurement methods in the research of sensitive issues as attitudes towards violence, where participants tend to provide socially desirable answers, when using self-report measures, especially, when the sample is violent offenders.

The results showed a partial correspondence between the results of implicit and explicit measurements of attitudes towards violence. The difference of the strength of explicit criminal attitude towards violence between the groups "Not Sentenced" and "Sentenced" was not revealed, but implicit associations of oneself with non-violence are more pronounced in the "Not Sentenced" group. In the "Not Sentenced" group, the part of participants with the secure attachment style is greater than in the "Sentenced" group. The relationships between measurements of attachment styles (secure, insecure avoidant and insecure anxious) and attitudes towards criminal violence only with explicit attitudes were revealed. Non offenders with secure attachment style have the least pronounced explicit attitudes towards criminal violence, compared with the males with insecure attachment styles.

For future directions it is necessary to include the influence of contextual factors on implicit measurements of attitude towards violence and introduce Subliminal Evaluative Priming as implicit measure of violence. It will allow to understand the mechanisms of formation and change of violent attitudes.

\section{Bibliography}

1. Ainsworth M.D.S., Blehar M.C., Waters E., Wall S. (1978). Patterns of Attachment: A Psychological Study of the Strange Situation. Hillsdale, NJ: Lawrence Erlbaum Associates.

2. Ansbro M. (2008). Using Attachment theory with Offenders. Probation Journal, 55(3), 231-244. doi: 10.1177/0264550508092812

3. Baker E., Beech A. R. (2004). Dissociation and Variability of Adult Attachment Dimensions and Early Maladaptive Schemas in Sexual and Violent Offenders. Journal of Interpersonal Violence, 19, 1119-1136. doi: 10.1177/0886260504269091

4. Barrett P.M., Holmes J. (2001). Attachment Relationships as Predictors of Cognitive Interpretation and Response Bias in Late Adolescence. Journal of Child and Family Studies, 10, 51-64. doi: 10.1023/A:1016677416638

5. Bartholomew K., Horowitz L.M. (1991). Attachment Styles Among Young Adults: A Test of a Four-Category Model. Journal of Personality and Social Psychology, 61(2), 226-244. doi: 10.1037/0022-3514.61.2.226

6. Bifulco A., Mahon J., Kwon J.H., Moran P.M., Jacobs C. (2003). The Vulnerable Attachment Style Questionnaire (VASQ): An Interview-based Measure of Attachment Styles that Predict Depressive Disorder. Psychological Medicine, 33(6), 1099-1110. doi: 10.1017/s0033291703008237

7. Blumenthal S., Gray N.S., Shuker R., Wood H., Fonagy P., Allonby M., Flynn A., Takala T., Snowden R.J. (2019). Implicit measurement of violence-related cognitions. Psychology of Violence, 9(2), 235-243. doi: 10.1037/vio0000194 
8. Bosson J.K., Swann W.B., Pennebaker, J.W. (2000). Stalking the Perfect Measure of Implicit Self-esteem: The Blind Men and The Elephant Revisited. Journal of Personality and Social Psychology, 79, 631-643. doi: 10.1037/0022-3514.79.4.631

9. Boswell G. (1998). Research-Minded Practice with Young Offenders Who Commit Grave Crimes. Probation Journal, 45(4), 202-297. doi: 10.1177/026455059804500402

10. Bowes N., McMurran M. (2013). Cognitions Supportive of Violence and Violent Behavior. Aggression and Violent Behavior, 18(6), 660-665. doi: 10.1016/j.avb.2013.07.015

11. Bowlby J. (1944). Forty-four Juvenile Thieves: Their Characters and Home Lives. International Journal of Psycho-Analysis, XXV, 19-52

12. Bowlby J. (1973). Attachment and loss: Vol. 2. Separation: Anxiety and anger. New York: Basic Books. Retrieved from https://www.abebe.org.br/files/John-Bowlby-Separation-Anxiety-AndAnger-Attachment-and-Loss-Vol-2-1976.pdf

13. Bowlby J. (1984). Violence in the Family as a Disorder as the Attachment and Caregiving Systems. American Journal of Psychology, 44(1), 9-27. doi: 10.1007/BF01255416

14. Bowlby J. (1988). A Secure Base: Parent-child Attachment and Healthy Human Development. New York: Basic Books.

15. Briere J. (1992). Methodological Issues in the Study of Sexual Abuse Effects. Journal of Consulting and Clinical Psychology, 60(2), 196-203. Retrieved from

https://www.researchgate.net/publication/21562679

16. Farrington D.P. (2007). Childhood risk factors and risk-focused preventions. In M. Maguire, R Morgan, R. Reiner (Eds.), The Oxford Handbook of Criminology (4th ed.). Oxford: University Press.

17. Fazio R.H., Olson M.A. (2003). Implicit measures in social cognition research: Their meaning and use. Annual Review of Psychology, 54, 297-327. doi: 10.1146/annurev.psych.54.101601.145225

18. Fonagy P. (2004). The Developmental Roots of Violence in the Failure of Mentalization. In F. Pfäfflin, G. Adshead (Eds.), A Matter of Security: The Application of Attachment Theory to Forensic Psychiatry and Psychotherapy, 13-56. London and New York: Jessica Kingsley Publishers.

19. Gray N.S., MacCulloch M.J., Smith J., Morris M., Snowden R.J. (2003). Violence Viewed by Psychopathic Murderers. Nature, 423, 497-498. doi: 10.1038/423497a

20. Greenwald A.G., McGhee D.E., Schwartz J.L.K. (1998). Measuring Individual Differences in Implicit Cognition: The Implicit Association Test. Journal of Personality and Social Psychology, 74(6), 1464-1480. doi: 10.1037/0022-3514.74.6.1464

21. Hazan C., Shaver P.R. (1994). Attachment as an Organizational Framework for Research on Close Relationships. Psychological Inquiry, 5(1), 1-22. Retrieved from http://apegosposibles.com/sites/default/files/hazanandshaver.pdf

22. Hoeve M., Stams G.J.J.M., van der Put C.E., Dubas J.S., van der Laan P.H., Gerris J.R.M. (2012). A Meta-analysis of Attachment to Parents and Delinquency. Journal of Abnormal Child Psychology, 40(5), 771-785. doi: 10.1007/s10802-011-9608-1

23. Johnson S.M., Makinen J.A., Millikin J.W. (2001). Attachment Injuries in Couple Relationships: A New Perspective On Impasses in Couples Therapy. Journal of Marital and Family Therapy,27(2), 145-155. doi: 10.1111/j.1752-0606.2001.tb01152.x

24. Karpinski A., Hilton J. L. (2001). Attitudes and the Implicit Association Test. Journal of Personality and Social Psychology, 81(5), 774-788. doi: 10.1037/0022-3514.81.5.774

25. Meesters C., Muris P. (2002). Attachment Style and Self-reported Aggression. Psychological Reports, 90(1), 231-235. doi: 10.2466/pr0.2002.90.1.231

26. Mikulincer M., Shaver P.R. (2007). Attachment in adulthood: structure, dynamics, and change. New York: Guilford Press.

27. Miller S., Klockner K. (2019). Attachment Styles and Attachment Based Change in Offenders in a Prison Therapeutic Community. Journal of Forensic Psychology Research and Practice, 19(3), 260-277. doi: 10.1080/24732850.2019.1603956

28. Ottaway S.A., Hayden D.C., Oakes M.A. (2001). Implicit Attitudes and Racism: Effects of Word Familiarity and Frequency on the Implicit Association Test. Social Cognition, 19(2), 97-144. doi: 10.1521/soco.19.2.97.20706

29. Parsons M. (2009). The Roots of Violence. In M. Lanyado, A. Horne (Eds.), The Handbook of Child and Adolescent Psychotherapy. Psychoanalytic approaches ( $2^{\text {nd }}$ ed.). London: Routledge. doi: $10.4324 / 9780203877616$ 
30. Plotka I., Simane-Vigante L., Blumenau N. (2018). Implicit association Self-concept test in studying of violence-related cognitions. Social psychology and society, 9(3), 176-185. doi: $10.17759 /$ sps.2018090317

31. Polaschek D.L.L., Bell R.K., Calvert S.W., Takarangi M.K.T. (2010). Cognitive-behavioural Rehabilitation of High-risk Violent Offenders: Investigating Treatment Change with Explicit and Implicit Measures of Cognition. Applied Cognitive Psychology, 24(3), 437-449. doi: 10.1002/acp.1688

32. Polaschek D.L.L., Collie R.M., Walkey F.H. (2004). Criminal attitudes to violence: Development and preliminary validation of a scale for male prisoners. Aggressive Behavior, 30(6), 484-503. doi: 10.1002/ab.20081

33. Ross T., Pfäfflin F. (2007). Attachment and Interpersonal Problems in a Prison Environment. The Journal of Forensic Psychiatry \& Psychology, 18(1), 90-98. doi: 10.1080/14789940601063345

34. Rudman L. A. (2011). Implicit measures for social and personality psychology. Rutgers University, USA: SAGE Publications. doi: 10.4135/9781473914797

35. Shaver P.R., Balsky J., Brennan K.A. (2000). The Adult Attachment Interview and Self- reports of Romantic Attachment: Associations across Domains and Methods. Personal relationships, 7(1), 25-43. doi: 10.1111/j.1475-6811.2000.tb00002.x

36. Simane-Vigante L., Plotka I., Blumenau N. (2018). Research of the Relationship of Criminal Violence, Adult Attachment Styles and Personality Traits of Violent Male Offenders. In V. Dislere (Ed.), The Proceedings of the International Scientific Conference Rural Environment, Education, Personality (REEP), 11. Jelgava: Latvia University of Life Sciences and Technologies, 128-141. doi: 10.22616/REEP.2018.015

37. Simons D. A., Wurtele S. K., Durham R. L. (2008). Developmental Experiences of Child Sexual Abusers and Rapists. Child Abuse \& Neglect, 32(5), 549-560. doi: 10.1016/j.chiabu.2007.03.027

38. Snowden R., Gray N. Smith J., Morris M., MacCulloch M. (2004). Implicit Affective Associations to Violence In Psychopathic Murderers. Journal of Forensic Psychiatry and Psychology, 15(4), 620-641. doi: 10.1080/14789940412331313377

39. Spangler G., Schieche M. (1998). Emotional and Adrenocortical Responses of Infants to the Strange Situation: The Differential Function of Emotional Expression. International Journal of Behavioral Development, 22(4), 681-706. doi: 10.1080/016502598384126 